\title{
Dental Implant Placement without Grafting in a Young Patient with a Large Cyst Defect
}

\author{
Banu Gürkan Köseoğlu, Çağrı Akçay, Neşe Kahraman, Melek Koltuk and Hülya Koçak Berberoğlu \\ ${ }^{1}$ Department of Oral Surgery, Istanbul University, Turkey
}

Submission: September 27, 2016; Published: October 13, 2016

*Corresponding author: Çăgrı Akçay, Department of Oral Surgery, Faculty of Dentistry Oral and Maxillofacial Surgery, Istanbul University, 0. Floor, Ãłapa Fatih, Istanbul, Turkey

\begin{abstract}
Odontogenic cysts are the most common form of cystic lesions that affect the maxillofacial region. After removal of cysts, large defects can occur in the cyst region. Due to occurence of large defects before dental implantation different grafting methods should be used to make the bone adequate for implant operation. The purpose of this study is to show the healing of bone defects in young patients without grafting is unexpectedly as well as grafted defects.

Keywords: Implant; Grafts; Cbct; Cyst
\end{abstract}

\section{Introduction}

Odontogenic cysts are the most common form of cystic lesions that affect the maxillofacial region. $60 \%$ of all jaw cysts are radicular or residual cysts [1-3]. Patients in their second and third decades of life are affected most commonly. Radicular cysts can occur in the periapical area of any teeth, at any age but are seldom seen associated with the primary dentition [4]. The most frequent cyst of the teeth bearing areas is the radicular, also called periapical or apical cyst. Radicular cyst arise from the proliferation of the epithelial remnants of Malassez rest in response to stimulation of chronic inflammatory processes in the apical region of the necrotic tooth. This cyst is classified as inflammatory, because in the majority of cases it is a consequence to pulpalnecrosis following caries, with an associated periapical inflammatory response [3-6]. Dental implants require sufficient bone to be adequately stabilised. Augmentation grafting adds strenght to an extremely deficient maxilla and improves the height and contour of the available bone for implant placement on the denture-bearing areas. However in young patients bone healing is suprisingly as good as grafting. The purpose of this study is to show the healing of bone defects in young patients without grafting is unexpectedly as well as grafted defects.

\section{Case Report}

In 2009, a patient referred to Istanbul University, Faculty of Dentistry, Department of Oral Surgery with a swelling and pain in his right mandible. Radiological examination revealed that a well-circumscribed radiolucency in the posterior right mandible (Figure 1-3). Clinical and radiological findings look like cystic ameloblastoma, operation was made without grafting. The patient did not accepted grafting. The pathologic lesion was enuclated and two molars were extracted. Histopathological diagnose was radicular cyst. After one year, the healing of the bone was unexpectedly perfects odental implant surgery was planned under CBCT (Figures 4 \& 5). Two implants were placed (Figures $6 \& 7$ ). The patient is under follow up approximately 2 years after implant surgery without any complications.

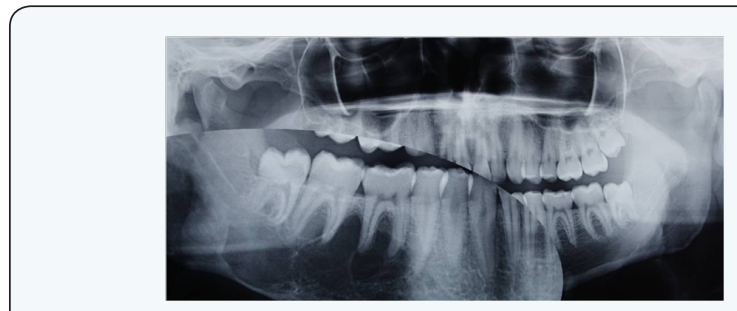

Figure 1: Radiological examination revealed that a wellcircumscribed radiolucency in the posterior right mandible.

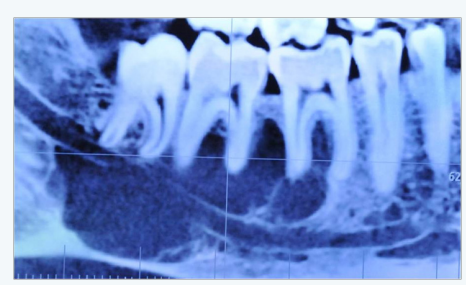

Figure 2: Radiological examination revealed that a wellcircumscribed radiolucency in the posterior right mandible. 


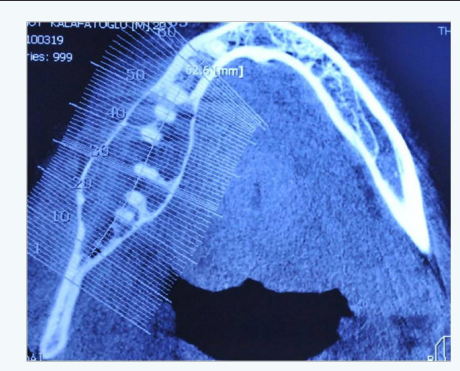

Figure 3: Radiological examination revealed that a wellcircumscribed radiolucency in the posterior right mandible.

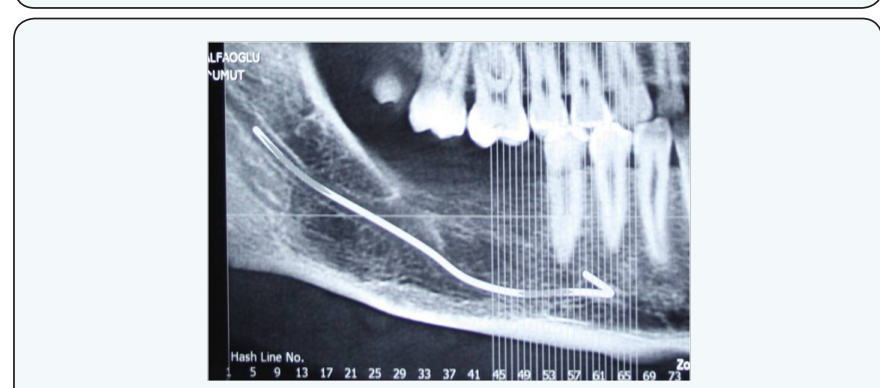

Figure 4: Histopathological diagnose was radicular cyst. After one year, the healing of the bone was unexpectedly perfects odental implant surgery was planned under CBCT.

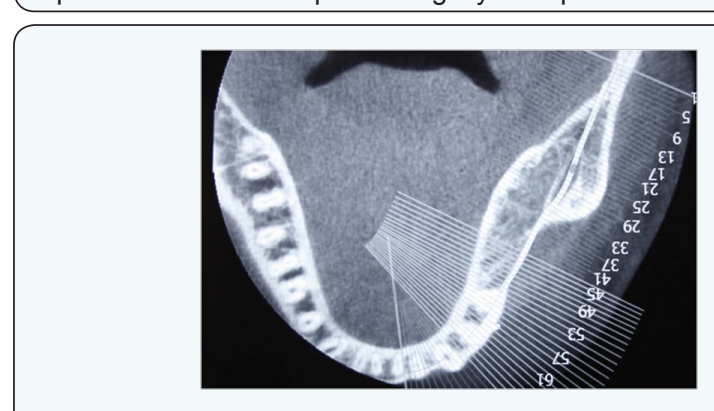

Figure 5: Histopathological diagnose was radicular cyst. After one year, the healing of the bone was unexpectedly perfects odental implant surgery was planned under CBCT.

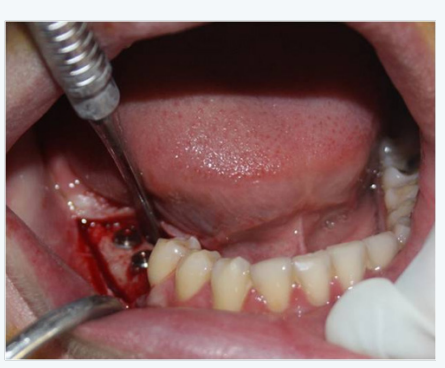

Figure 6: Two implants were placed.

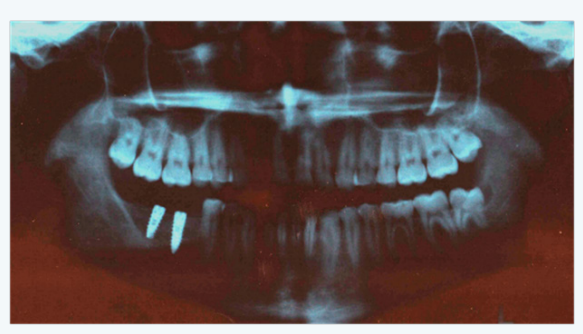

Figure 7: Two implants were placed.

\section{Discussion}

Cysts are more common in the jaws than in anyother bone because of the ubiquitous of epithelial rests after odontogenesis. Nakamura et al. [4,5] reported that in a survey of 1234 odontogenic cystic lesions, $41.2 \%$ were diagnosed as radicular cysts, $27 \%$ as dentigerous cysts $7.7 \%$ as odontogenickeratocysts and $21.6 \%$ as postoperative maxillary cysts. Within the last two decades, the use of osseointegrated implants to replace missing maxillary central and lateral incisors has become a common treatment solution for patients 20 years and older. Clinical success depends not only on persisting osseointegration but also on harmonious integration of the crown in the dental arch [711]. A dental bone graft is deemed as a necessity when the jaw bone does not have sufficient bone to support and stabilize the dental implants. A variety of materials and surgical techniques are available for bone augmentation.On the other hand young patients have a chance of stimulated bone healing with the young cells. In clinical and experimental studies, the use of implants has become a popular and accepted treatment to partial and total missing teeth. The long-term success of oral implants in adult patients has encouraged clinicians to broaden the use of implants to young patients missing one or more teeth due to pathologic lesions or trauma $[2,9,11]$.

\section{Conclusion}

Dental implants are the best solution, for replacement of missing teeth. In younger patients, healing of the bone is usually as well as grafted defects. Especially in the cases of treated jaw cysts or benign tumours, the prosthetic rehabilitation with dental implants can give very good aesthetic and functional results. However, a long term follow up is necessary because of complications such as cyst recurrences or implant failure.

\section{References}

1. Chirapathomsakul D, Sastravaha P, Jansisyanont P (2006) A review of odontogenic keratocysts and the behaviour of recurrences. Oral Surg Oral Med Oral Pathol Oral Radiol Endod 101(1): 59-62.

2. McAllister BS, Haghighat K (2007) Bone augmentation techniques. J Periodontol 78(3): 377-396.

3. Nakamura T, Ishida J, Nakano Y, Ishii T, Fukumoto M, et al. (1995) A study of cysts in the oral region. Cysts of the jaw. J Nihon Univ Sch Dent 37(1): 33-40.

4. Koseoglu BG, Atalay B, Erdem MA (2004) Odontogeniccysts: a clinicalstudy of 90 cases. J Oral Sci 46(4): 253-257.

5. Koseoglu BG, Olgac V (2004) Odontogenic peripheral myxo fibroma of the maxilla: an unusual case report. Bull Kanagawa Dent Col 32: 89-92.

6. Ochsenius G, Escobar E, Godoy L, Peñafiel C (2007) Odontogenic cysts: Analysis of 2.944 cases in Chile. Med Oral Patol Oral Cir Bucal 12(2): 85-91.

7. Barry CP, Kearns GJ (2003) Case report- odontogenic keratocysts: enucleation, bone grafting and implant placement: an early return to function. J Ir Dent Assoc 49(3): 83-88.

8. Galzignato PF, Sivolella S, Cavallin G, Ferronato G (2010) Dental implant failure associated with a residual maxillary cyst. Br Dent J 208(4): 380385 . 
9. Regezi JA (2002) Odontogenic cysts, odontogenic tumors, fibroosseous and giant cell lesions of the jaws. Mod Pathol 15(3): 331-341.

10. Karamanis S, Kitharas T, Tsoukalas D, Parissis N (2006) Implant placement after marsupialization of a dentigerous cyst. J Oral Implantol 32(6): 313-316
11. Sakamoto E, Shimada J, Takeshima H, Yamazaki Y, Shimazaki T, et al. (1990) Reconstruction of occlusal function with osseointegrated implant following mandibular resection. Meikai Daigaku Shigaku Zasshi 19(3): 424-436.

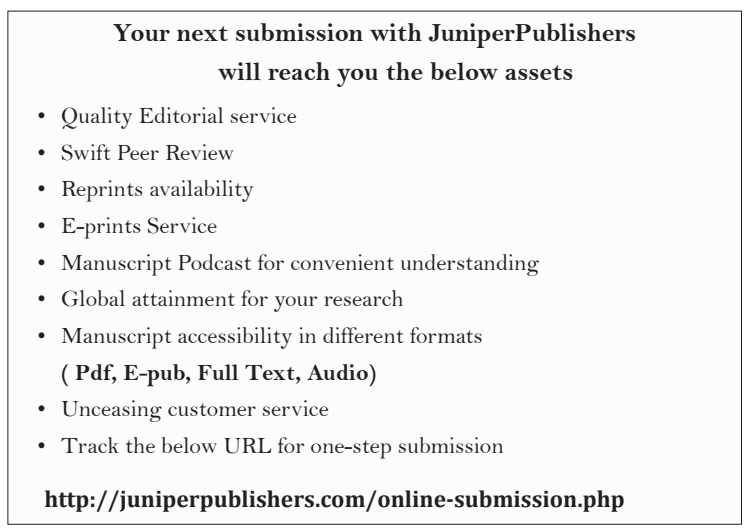

